\title{
Research made simple: developing complex interventions
}

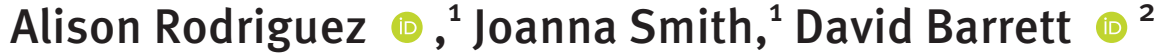

10.1136/ebnurs-2020-103261

${ }^{1}$ School of Healthcare, University of Leeds, Leeds, UK

${ }^{2}$ Faculty of Health Sciences, University of Hull, Hull, UK

Correspondence to:

Dr Alison Rodriguez, School of Healthcare, University of Leeds, Leeds, UK; a.m.rodriguez@ leeds.ac.uk
In common with many other countries, population ageing, advancements in medical technology, changing disease profiles, the influence of lifestyle choices on health and increased patient expectations are driving health and social care provision in the UK. As the number of people living with one or more long-term conditions rises, interventions to support their health and well-being become increasingly complex. Nurses will not only be expected to deliver complex interventions but are in an ideal position to contribute to priority setting and the development and evaluation of interventions that meet patient needs. It is essential that complex interventions are based on the best available evidence and evaluated if they are to improve health outcomes. In this article we will provide an overview of complex interventions, using dignity therapy as an example, and outline the principles of developing a complex intervention.

\section{What is a complex intervention?}

The UK Medical Research Council (MRC) defines complex interventions as those with several interacting components. ${ }^{1}$ In addition, interventions can be thought of as complex if they are dependent on the behaviours of those delivering and receiving the intervention, there are a range of possible outcomes, or there is a need to tailor the intervention to different contexts and settings. ${ }^{1}$

In palliative and end of life care (EoLC) settings, helping people make sense of their lives is as important as managing disease symptoms. Dignity therapy (DT) is

\begin{tabular}{|c|c|}
\hline Activities & Considerations \\
\hline Planning & $\begin{array}{l}\text { Identify the problem, and why a change is required, its importance and what would be the benefits of a new } \\
\text { intervention. Identify current interventions-what does and does not work. Identify resources required both in terms of } \\
\text { time (be realistic) and funding } \\
\text { Understand the context (population and individuals; location or geographical setting; social, economic, cultural and } \\
\text { political influences) where the intervention will be implemented. Understand the facilitators and barriers to reaching } \\
\text { the relevant population }\end{array}$ \\
\hline $\begin{array}{l}\text { Involve } \\
\text { stakeholders }\end{array}$ & $\begin{array}{l}\text { Identify and involve all stakeholders (commissioners of services, health professionals who deliver interventions, and } \\
\text { patients and carers who will benefit from the intervention) throughout the development process } \\
\text { It may be appropriate to adjust eligibility criteria for participants in EoLC in order to recruit patients who may } \\
\text { benefit the most from the intervention }\end{array}$ \\
\hline The team & $\begin{array}{l}\text { It is essential the development team includes individuals with relevant expertise in relation to the problem being } \\
\text { addressed, including stakeholders, and the methodological experts to support the collection of evidence } \\
\text { Researchers need to be familiar with the challenges in EoLC studies. Ideally involvement with stakeholders would } \\
\text { be established prior to the study and continue beyond individual studies. It is also important to minimise the } \\
\text { burden for clinical staff who participate }\end{array}$ \\
\hline $\begin{array}{l}\text { Establish the } \\
\text { evidence-base }\end{array}$ & $\begin{array}{l}\text { Review and synthesis published research evidence before starting to develop the intervention to understand the } \\
\text { evidence base for each component of the intervention }\end{array}$ \\
\hline Draw on theory & $\begin{array}{l}\text { Identify existing theory/ theories or frameworks that will inform the development of the intervention, eg, psychological } \\
\text { and organisational theories }\end{array}$ \\
\hline $\begin{array}{l}\text { Develop and } \\
\text { design the } \\
\text { intervention }\end{array}$ & $\begin{array}{l}\text { Collect qualitative data to generate ideas about the content, format and delivery of the intervention. Identify outcomes } \\
\text { and what measures exist to evaluate outcomes using quantitative methods } \\
\text { EoLC measures should be chosen that meet the following criteria: } \\
\text { Established validity and reliability in a relevant population } \\
\text { Responsive to change over time } \\
\text { Capture clinically important data } \\
\text { Easy to administer and interpret (concise and not complex) } \\
\text { Applicable across care settings to capture a change in outcomes by location (eg, home, hospice and hospital) } \\
\text { Able to be integrated into clinical care } \\
\text { Minimise problems of response shift (a change in conceptualisation or calibration of what is being measured) } \\
\text { In addition, and central to complex interventions is the experience of 'care'- allowing enough time for the } \\
\text { intervention to have had an effect is important. The plan of investigation and methods should not cause } \\
\text { unnecessary burden on participants. The therapeutic effect of interviewing, if a component of the intervention } \\
\text { should also be considered during evaluation }\end{array}$ \\
\hline $\begin{array}{l}\text { Testing the } \\
\text { intervention }\end{array}$ & $\begin{array}{l}\text { Write up the intervention development process so that judgments can be made about the quality of the process. } \\
\text { Develop a protocol for the feasibility/pilot or evaluation of the intervention } \\
\text { Consider issues of attrition when developing protocols in EoLC, because attrition rates can influence decisions } \\
\text { during the implementation of interventions. Estimate in advance possible reasons for attrition and missing data } \\
\text { when calculating sample sizes and allow for data collection phases from proxies. Use the MORECare classification } \\
\text { to describe the causes of attrition: } \\
\text { Attrition due to death } \\
\text { Attrition due to illness } \\
\text { Attrition at random } \\
\text { Consider implementation implications, eg, workforce and training needs at all stages of intervention } \\
\text { development, testing and integration into practice. } \\
\text { Data on the use of services needs to be collected to explore impacts on care costs } \\
\text { Cost-effectiveness outcome measures need to be justified }\end{array}$ \\
\hline
\end{tabular}




\begin{tabular}{|c|c|c|}
\hline Role preservation & $\begin{array}{l}\text { Being able to maintain an association with one or more } \\
\text { previously held roles }\end{array}$ & $\begin{array}{l}\text { Patients are invited to talk about previous or current roles that } \\
\text { integral to their perceived identity }\end{array}$ \\
\hline $\begin{array}{l}\text { Maintenance of } \\
\text { pride }\end{array}$ & An ability to maintain positive self-regard & $\begin{array}{l}\text { Patients are invited to talk about achievements or key memories } \\
\text { that have enabled them to experience a sense of pride }\end{array}$ \\
\hline Hopefulness & $\begin{array}{l}\text { An ability to see, achieve and maintain a sense of } \\
\text { meaning or purpose }\end{array}$ & $\begin{array}{l}\text { Patients are invited to engage in a therapeutic process that will help } \\
\text { them to achieve a sense of their meaning and purpose }\end{array}$ \\
\hline Care tenor & $\begin{array}{l}\text { The attitude and manner of others when interacting with } \\
\text { the patient to promote dignity }\end{array}$ & $\begin{array}{l}\text { The tenor of dignity therapy aims to be empathic, non-judgmental, } \\
\text { encouraging and respectful }\end{array}$ \\
\hline
\end{tabular}

DCMC, Dignity Conserving Model of Care; DT, dignity therapy.

a validated psychotherapeutic intervention designed to bring about a sense of meaning and purpose for individuals at the end of life. ${ }^{2}$ DT addresses psychosocial and existential distress by encouraging patients through focused interviews to discuss valued memories, accomplishments, roles, life lessons and hopes for significant others. Interviews are recorded, transcribed, edited and transcripts returned to the patient, who can add to the document. The format of the documents, typically labelled a 'generativity document' or 'written legacy', is evolving, for example, picture books, including cherished photos alongside briefer key commentaries. Many patients share these documents with significant others, providing opportunity for meaningful conversations that can assist with the bereavement processes. DT can be thought of as a complex intervention because: (1) DT is dependent on the skills of professionals delivering the intervention and the receptiveness of those receiving the intervention; (2) there are a range of outcomes measures that can evaluate the effectiveness of DT such as the Dignity Impact scale ${ }^{3}$ (a new measure specifically developed as an outcome measure for DT, measuring influences on the spiritual domain of well-being including meaning making, preparation for death and life completion tasks), The Palliative Performance Scale ${ }^{4}$ (assesses psychological, existential and spiritual distress), anxiety/ depression scales ${ }^{5}$ and the patient dignity inventory ${ }^{6}$ (a measure of dignity-related distress); (3) DT needs to be tailored to different service settings and patient illness trajectories.

\section{What are the key stages in developing a complex intervention?}

Although MRC guidance on complex intervention ${ }^{1}$ has been in existence since 2000, methodological development is continuing to progress at a rapid pace. Although multicomponent interventions will be necessary to support patients and their families in an increasingly complex healthcare environment, the reporting of complex interventions has been criticised for not always including all 'ingredients' of the intervention. ${ }^{7}$ For intervention development to be successful, rigorous, structured and methodologically appropriate processes must be followed. ${ }^{8}$ Involvement of stakeholders throughout the development process is central to producing an intervention that is fit for purpose that meets both health professional and patient needs, and ensures implementation is well-adopted. ${ }^{9}$ Furthermore, the MRC guidelines on complex intervention development emphasise that interventions must be theory-driven in order to understand how they work and in order to achieve the best outcomes. ${ }^{1}$ A poorly conceptualised phenomenon results in interventions that are rarely well developed. ${ }^{10}$

The Methods of Researching End of life Care (MORECare) ${ }^{11}$ statement builds on the MRC guidance in relation to best practice and solutions to developing and evaluating complex interventions within EoLC. It is important to combine MRC guidance with guidance that supports best practice in terms of research design/ population needs. ${ }^{11}$ Table 1 provides a brief summary of the stages that guide the development of complex interventions based on a widely adopted framework developed by 0'Cathain and colleagues, combined with components of the MORECare statement that are particularly pertinent to EoLC interventions, such as DT. ${ }^{811}$ In addition to effective planning and meaningful stakeholder engagement, the development of a complex intervention includes synthesising the evidence, understanding how the intervention would changes behaviours by drawing on existing theory, and patient-focused research to identify its components.

In relation to DT, the intervention evolved from the Dignity Conserving Model of Care (DCMC). ${ }^{12}$ The DCMC, the theoretical/conceptual framework underpinning DT was developed from detailed qualitative work. Participants comprised a range of stakeholders including patients and their families, who were invited to explore what constitutes dignity and how it can be achieved or maintained through experiences, cares and interactions. The model contains several themes and related subthemes that informed the schedule of questions and tenor of $\mathrm{DT}^{2}$ Table 2 provides a brief summary of each theme/component of the DCMC ${ }^{12} 13$ and highlights how each theme has influenced DT. Following its initial development, the effectiveness 
of DT has been studied in feasibility and randomised control trial studies to evaluate its value for different patient populations and their families. ${ }^{14}$ To date, DT is proving to be a supportive psychotherapeutic intervention for middle-aged and older adults. ${ }^{14}$ However, further studies are required to develop DT as a complex intervention to support the needs of younger lifelimited populations. ${ }^{15} 16$

In summary, we offer some key considerations to successful complex intervention development in healthcare, with additional considerations for EoLC studies, highlighting through the example of DT as a complex intervention. Research evidence, using mixed methods approaches and theory, inform the content, structure and delivery of complex interventions to increase the likelihood of them being effective. Collaboration with stakeholders through all stages of development, testing and implementation can enhance the perceived value, efficacy and effectiveness of complex interventions.

Twitter Alison Rodriguez@ARodriguez339, Joanna Smith@josmith175 and David Barrett @barrett1972

Funding The authors have not declared a specific grant for this research from any funding agency in the public, commercial or not-for-profit sectors.

Competing interests DB is an Associate Editor for Evidence Based Nursing Journal.

Patient consent for publication Not required.

Provenance and peer review Not commissioned; internally peer reviewed.

- Author(s) (or their employer(s)) 2020. No commercial re-use. See rights and permissions. Published by BMJ.

ORCID iDs

Alison Rodriguez http://orcid.org/0000-0001-91041999

David Barrett http://orcid.org/0000-0003-4308-4219

\section{References}

1 Craig P, Dieppe P, Macintyre S, et al. Developing and evaluating complex interventions: the new medical Research Council guidance. The BMJ 2008;337.
2 Chochinov HM, Hack T, Hassard T, et al. Dignity therapy: a novel psychotherapeutic intervention for patients near the end of life. J Clin Oncol 2005;23:5520-5.

3 Scarton L, Oh S, Sylvera A, et al. Dignity impact as a primary outcome measure for dignity therapy. Am J Hosp Palliat Care 2018;35:1417-20.

4 Anderson F, Downing GM, Hill J, et al. Palliative performance scale (PPS): a new tool. J Palliat Care 1996;12:5-11.

5 Snaith RP. The hospital anxiety and depression scale. Health Qual Life Outcomes 2003;1:29.

6 Chochinov HM, Hassard T, McClement S, et al. The patient dignity inventory: a novel way of measuring dignityrelated distress in palliative care. J Pain Symptom Manage 2008;36:559-71.

7 Harris J, Croot L, Thompson J, et al. How stakeholder participation can contribute to systematic reviews of complex interventions. J Epidemiol Community Health 2016;70:207-14.

8 0'Cathain A, Croot L, Duncan E, et al. Guidance on how to develop complex interventions to improve health and healthcare. BMJ Open 2019;9:e029954.

9 Turner KM, Rousseau N, Croot L, et al. Understanding successful development of complex health and healthcare interventions and its drivers from the perspective of developers and wider stakeholders: an international qualitative interview study. BMJ Open 2019;9:e028756.

10 De Silva MJ, Breuer E, Lee L, et al. Theory of change: a theorydriven approach to enhance the medical Research Council's framework for complex interventions. Trials 2014;15:267.

11 Higginson IJ, Evans CJ, Grande G, et al. Evaluating complex interventions in end of life care: the MORECare statement on good practice generated by a synthesis of transparent expert consultations and systematic reviews. BMC Med 2013;11:111-22.

12 Chochinov HM. Dignity-conserving care--a new model for palliative care: helping the patient feel valued. JAMA 2002;287:2253-60.

13 Chochinov HM. Dignity Therapy: Final words for final days. New York: Oxford University Press, 2012.

14 Martínez M, Arantzamendi M, Belar A, et al. 'Dignity therapy', a promising intervention in palliative care: A comprehensive systematic literature review. Palliat Med 2017;31:492-509.

15 Rodriguez A, Smith J, McDermid K. Dignity therapy interventions for young people in palliative care: a rapid structured evidence review. Int J Palliat Nurs 2018;24:339-49.

16 Watts L, Rodriguez A, Tatterton M, et al. Meaning making and Generativity in children and young people with life limiting conditions (MAGICYL). Evid Based Nurs 2019;22:33-5. 